\title{
Predator-induced nest site preference: safe nests allow courtship in sticklebacks
}

\author{
ULRIKA CANDOLIN* \& HEINZ-RUDOLF VOIGT† \\ *Department of Biology, University of Turku \\ $\dagger$ Department of Limnology and Environmental Protection, University of Helsinki \\ (Received 23 January 1998; initial acceptance 9 March 1998; \\ final acceptance 8 April 1998; MS. number: 5760)
}

\begin{abstract}
Reproductive activities often increase the susceptibility of individuals to predators. Individuals may be able to reduce this risk of predation, however, by their choice of breeding habitat, as the structural complexity of habitats is known to affect predator foraging success. Here we show that the presence of predators induces a preference for structurally complex nest sites over open ones in male three-spined sticklebacks, Gasterosteus aculeatus. To investigate whether this predator-induced nest site preference can decrease the known negative effect of predators on courtship activity, we recorded the reduction in courtship activity during predator presentations for males in vegetated and open nest sites. Habitat structure affected the response to a predator when males were in competition. A male in a vegetated site reduced courtship activity less than a male in an open site. Habitat had no effect on courtship when males were solitary, however. This suggests that male-male competition and the possibility of losing mating opportunities to other males affect risk taking. Females, who were unaware of the predator, preferred the male in the vegetated site, which showed less reduction in courtship, when the males were exposed to a predator, but chose randomly between the males when the predator was absent. Thus, a preference for vegetated nest sites under predation risk may be beneficial not only by increasing the probability of survival, but also by reducing the negative impact of predators on courtship activity and mating probability.
\end{abstract}

(C) 1998 The Association for the Study of Animal Behaviour

During reproduction, individuals are often exposed to increased predation risk, owing to conspicuous courtship behaviours and coloration, increased predator encounters, or reduced agility and opportunity for escape (Gwynne 1989; Lima \& Dill 1990; Magnhagen 1991; Andersson 1994). Several studies have found that individuals try to reduce their susceptibility to predators by adjusting their reproductive tactics and characteristics to the risk of predation, for example by decreasing the intensity of courtship or nuptial coloration (Farr 1975; Endler 1983; Hastings 1991; Fuller \& Berglund 1996; Candolin 1997; Godin \& MacAulay 1997), switching to alternative reproductive strategies (Godin 1995 and references therein), or decreasing mating duration and frequency (Sih 1988; Sih et al. 1990). These changes in reproductive traits may also decrease mating success,

Correspondence: U. Candolin, Section of Ecology, Department of Biology, University of Turku, FIN-20014 Turku, Finland (email: ulrika.candolin@utu.fi). H.-R. Voigt is at the Department of Limnology and Environmental Protection, P.O. BOX 27, FIN-00014 University of Helsinki, Finland.

$0003-3472 / 98 / 111205+07 \$ 30.00 / 0$ however, and thus force individuals to trade current mating success against survival and future reproduction. In guppies, Poecilia reticulata, for instance, sneak copulation increases in frequency with increasing predation risk (Godin 1995), but is a less successful reproductive tactic than courtship display (Farr 1980; Houde 1988; Kodric-Brown 1993).

Vulnerability to predators may also depend on the structural complexity of the habitat. Increased vegetation has frequently been shown to decrease the susceptibility of individuals to predators by restricting the predator's movement and vision (e.g. Savino \& Stein 1982, 1989; Anderson 1984). Consequently, breeding individuals should be able to influence their risk of predation through their choice of breeding habitat. Only a few studies, however, have investigated the effect of predation risk on the choice of breeding habitat (see references in Sih 1994). Moreover, the consequences of predatorinduced shifts in breeding habitat on reproductive traits and mating success is even less well known.

In this study we investigated (1) whether the presence of predators affects the choice between two nest sites 
differing in structural complexity, and (2) how nest site complexity in turn affects male courtship behaviour and the probability of mating. We studied the three-spined stickleback, Gasterosteus aculeatus, a species in which breeding males are conspicuous to predators because of their elaborate courtship behaviours and bright breeding coloration. Earlier studies have found that males court less actively in the presence of predators and so are less attractive to females (Candolin 1997; Godin \& MacAulay 1997). Males show large variations in nest site preferences both within and between populations (reviewed by Rowland 1994; Whoriskey \& FitzGerald 1994) but the underlying cause of this variation is largely unknown. Differences in predation risk may be one of the factors that affect this variation (e.g. Moodie 1972), but so far no experimental studies have been carried out on this subject. Nest site characteristics, such as cover and water depth, influence male reproductive success in some populations (reviewed by Whoriskey \& FitzGerald 1994), but the interrelationship between predation risk, nest site characteristics and mating success has not been examined.

\section{METHODS}

We collected adult three-spined sticklebacks with fry traps from a shallow bay in the Baltic sea in southwestern Finland $\left(60^{\circ} \mathrm{N}, 23^{\circ} \mathrm{E}\right)$ at the beginning of May 1996 before the start of the breeding season. The fish were held in the laboratory in brackish water storage tanks (salinity $5.5 \%$ ), sexes separated, on an 18:6 h light:dark cycle at $15^{\circ} \mathrm{C}$ at a density of 10 fish per 125 -litre aquarium. They were fed twice daily to satiation with commercial flake food and chironomid larvae. The lack of suitable nesting materials and the high densities of fish discouraged breeding behaviour amongst males.

The predators, four perch, Perca fluviatilis, were collected with a seine from the same bay as the sticklebacks and maintained in a large holding aquarium $(150 \times 60 \mathrm{~cm}$, water depth $40 \mathrm{~cm})$ for 3 weeks. They were fed daily with live minnows. Perch is a natural predator on sticklebacks in the study area (personal observation).

\section{Ethical Note}

The sticklebacks showed no signs of distress during the 1-3 days of experimentation. All males showed normal breeding behaviour. Sticklebacks are stress tolerant and easily adapted to the laboratory. Live perch predators were used, as sticklebacks habituate to model predators (personal observation). The predators were fed live minnows as they did not accept alternative dead food. In total, 92 minnows were taken by the predators. Those not eaten within $10 \mathrm{~min}$ were removed and released back to the sea. The minnows showed no signs of distress. The sticklebacks and the perch were released at the site of capture after the experiments.

\section{Experiment 1: Choice of Nest Site}

In the experiment we investigated whether the presence of predators affects the choice between two nest sites differing in structural complexity. Two nesting dishes $(14 \mathrm{~cm}$ in diameter and filled with $1 \mathrm{~cm}$ of sand, an artificial plant and tufts of Cladophora as nesting material) were put into the opposite ends of an aquarium $(70 \times 45 \mathrm{~cm}$, water depth $30 \mathrm{~cm})$. A row of vegetation was put next to one of the nesting dishes to create a vegetated nest site, whereas the surroundings of the other nesting dish were left open (Fig. 1a). The row of vegetation $(5 \times 45 \times 25 \mathrm{~cm})$ consisted of 150 strings of green nylon ( $4 \mathrm{~mm}$ in diameter). Behind the male's aquarium was a large aquarium $(150 \times 60 \mathrm{~cm}$, water depth $40 \mathrm{~cm})$ that contained two perch (23 and $25 \mathrm{~cm}$ standard length, SL) in the predator treatments, and was left empty in the controls. White curtains with small viewing holes reduced external disturbances.

We individually tested 32 males for their choice of nest site, half of them in the presence of predators. One male at a time was placed into the aquarium for 1-3 days and we determined his choice of nest site by recording in which dish he built a complete nest. Usually males completed nest building within 1 day. We alternated the end of the aquarium at which the row of vegetation was placed between replicates. The males did not differ significantly in standard body length between the predator treatments and the controls $(\bar{X} \pm \mathrm{SD}=52.9 \pm 1.4$ and $53.0 \pm 1.5 \mathrm{~mm}$; $t$ test: $\left.t_{30}=0.12, \mathrm{NS}\right)$.

\section{Experiment 2. Effect of Nest Site on Courtship and Attractiveness}

To investigate whether the choice of nest site can affect the known negative effect of predators on courtship (Candolin 1997; Godin \& MacAulay 1997), we recorded the magnitude of predator-induced changes in courtship activity for males in vegetated and open nest sites. In the present study population, courtship consists mainly of zigzagging movements ('zigzags') in front of the female and leading her to the nest ('leads'). Because the presence of competing males can affect courtship (Candolin 1997), we carried out the experiment with both solitary and competing males courting a dummy female. Finally, we determined the effect of predator-induced changes in courtship activity on female mate choice.

\section{Solitary males}

Test aquaria $(45 \times 45 \mathrm{~cm}$, water depth $30 \mathrm{~cm})$ were divided by transparent Plexiglas into two compartments: a male compartment $(25 \times 45 \times 30 \mathrm{~cm})$ containing a nesting dish, and a predator presentation compartment $(20 \times 45 \times 30 \mathrm{~cm})$. We allowed 40 stickleback males to nest individually in the male compartments. Half of the males $(N=20)$ had a vegetated nest site, that is, a row of vegetation next to the nesting dish (Fig. 1b), and the rest of the males $(N=20)$ had an open nest site, that is, no row of vegetation. After a male had built a nest, we placed a realistic model of a gravid female in a head-up posture, which indicates readiness to spawn (ter Pelkwijk \& Tinbergen 1937), in front of the male's compartment for $10 \mathrm{~min}$ and recorded his courtship behaviour, that is, the frequency of zigzag bouts and leads, and the total time 

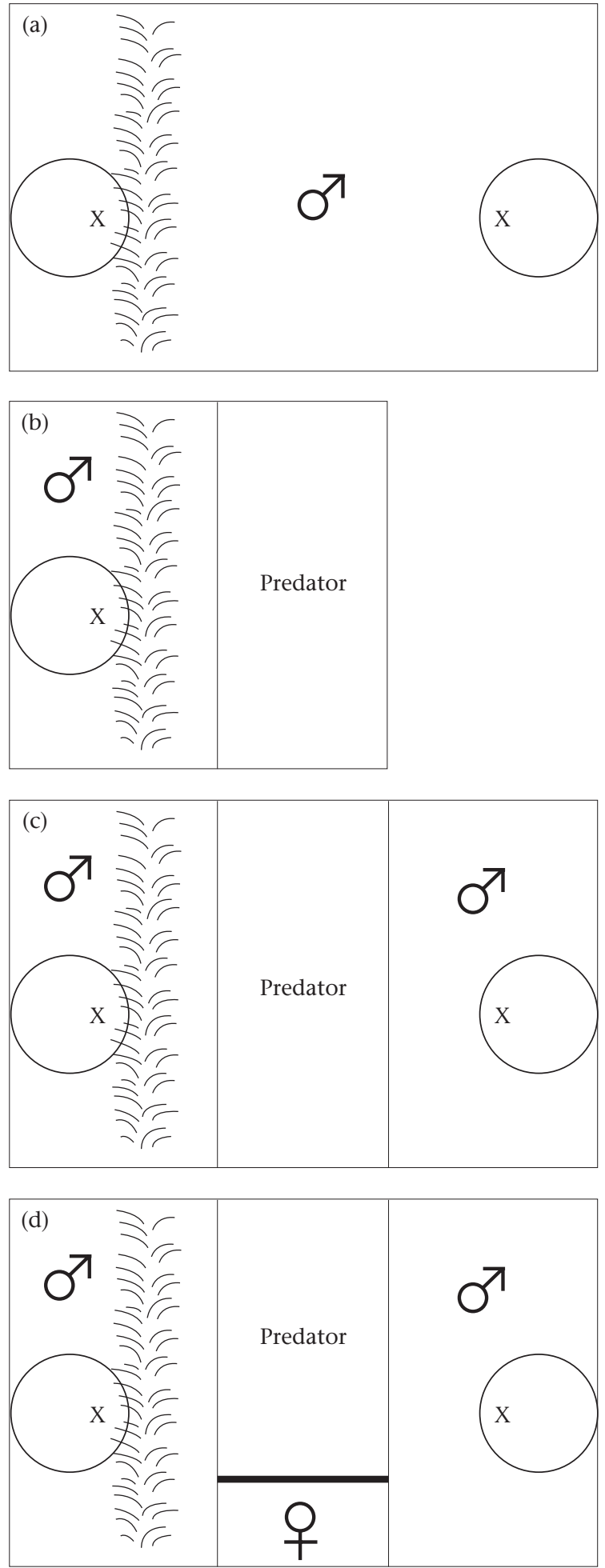

Figure 1. The experimental aquaria with nesting dishes and a row of vegetation. $X$ indicates the position of an artificial plant in the nesting dishes. (a) Experiment 1, (b) experiment 2 with solitary males, (c) with competing males and a dummy female, (d) with competing males and a live female.

spent engaged in courtship. This was done twice for each male, separated by $1 \mathrm{~h}$, once in the presence and once in the absence of a predator, a perch, 22-25 cm SL. We reversed the order of the predator and the control treatments in half of the replicates to eliminate possible effects of treatment order. We placed the predator into the predator compartment 2 min before presenting the female. We used a dummy female instead of live females to standardize female appearance and eliminate interactions between males and females that could affect male behaviour.

\section{Competing males}

Test aquaria $(70 \times 45 \mathrm{~cm}$, water depth $30 \mathrm{~cm})$ were divided by Plexiglas into three compartments: two male compartments $(25 \times 45 \times 30 \mathrm{~cm})$ with a predator compartment between them $(20 \times 45 \times 30 \mathrm{~cm})$. One of the male compartments had a vegetated nest site, and the other an open nest site (Fig. 1c). We allowed 20 male pairs to nest in the aquaria, one male in each male compartment. The males were matched for body length $( \pm 0.5 \mathrm{~mm})$ and ranged in size from 51 to $54 \mathrm{~mm}$ SL. Removable opaque sheets prevented the males from seeing each other during nest building. When both males had completed a nest, we removed the opaque sheets and allowed the males to habituate to each other for 1 day. Thereafter we placed the dummy female $10 \mathrm{~cm}$ in front of the predator section so that both males could see it, in both the presence and absence of a predator. The experimental procedures were the same as described for solitary males and the courtship behaviours were recorded for both males.

\section{Female mate choice}

The predator section in the aquaria used in the experiment with competing males was divided by an opaque sheet into a small female section measuring $20 \times$ $10 \times 30 \mathrm{~cm}$, and a larger predator section measuring $20 \times 35 \times 30 \mathrm{~cm}$ (Fig. 1d). The female section was sealed from the other compartments so that there was no visual or olfactory contact between the female and the predator section. We allowed 20 new male pairs, matched for body length $( \pm 0.5 \mathrm{~mm})$ and ranging in size from 50 to $53.5 \mathrm{~mm} \mathrm{SL}$, to nest in the aquaria. When both males in a male pair had built a nest, we presented three live gravid females sequentially to the males. The females were presented for $10 \mathrm{~min}$ each, after $2 \mathrm{~min}$ of acclimation, at intervals of $30 \mathrm{~min}$. They were presented in both the presence and absence of a predator, the treatments being separated by $1 \mathrm{~h}$, and the order reversed in half of the replicates. New females were used for each male pair. The sticklebacks were video filmed and the males' courtship behaviour and the time a female spent in a head-up posture facing each male were later recorded from the tapes.

As female mate choice can be based on both the courtship intensity and body coloration of males (reviewed by Rowland 1994), we determined any changes in colour difference between the two males. Two independent judges decided which of the two males in a pair appeared more colourful before and after female presentation. 

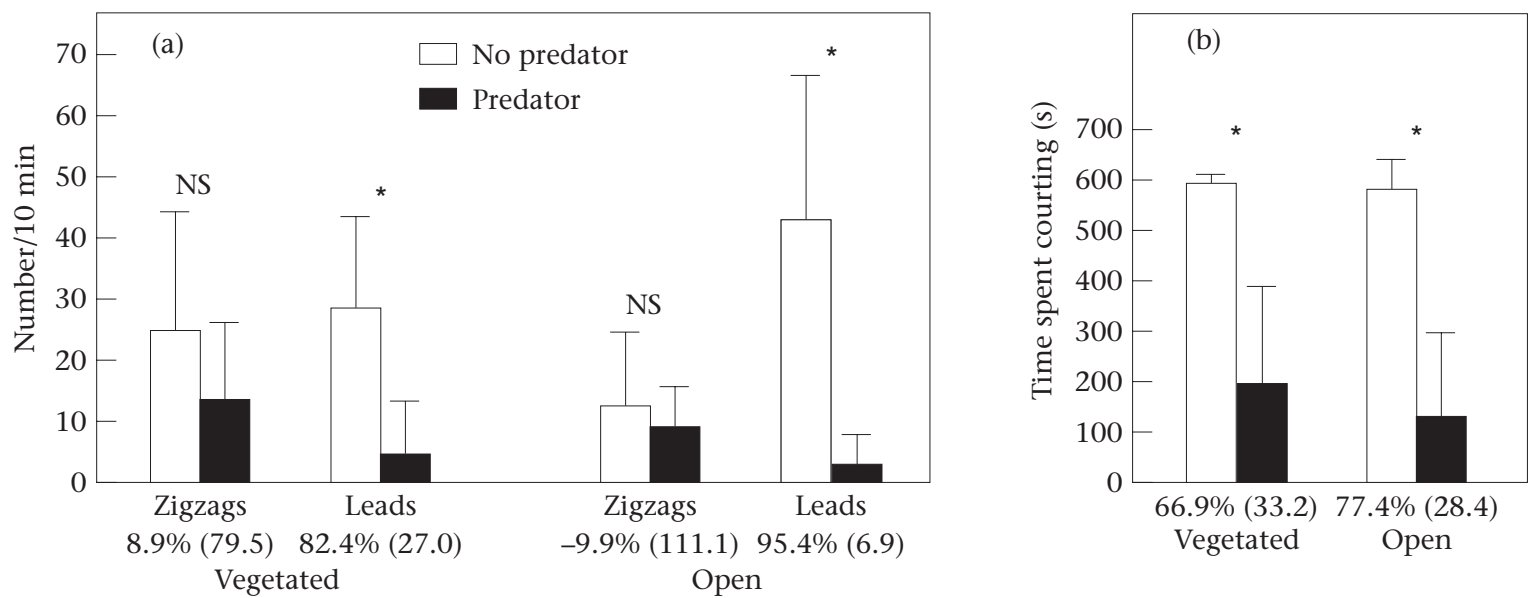

Figure 2. (a) Frequency of courtship behaviours and (b) time spent courting $(\bar{X}+\mathrm{SD})$ of solitary males with vegetated and open nest sites in the absence and presence of a predator, $N=20$. Wilcoxon signed-ranks test: vegetated nest site: zigzags: $Z=1.67$; leads; $Z=3.90$; time courting: $Z=3.90$; open nest site: zigzags: $Z=0.96$; leads: $Z=3.90$; time courting: $Z=3.80$; all $P_{S}<0.001$. Percentages below bars $(\bar{X}+S D)$ show the percentage decrease in the frequencies/time due to predator treatment.

\section{Data Analysis}

Changes in courtship activity, that is, changes in the frequencies of zigzags and leads, and the time spent courting, were recorded as proportions of the courtship activity without a predator: (courtship without predator - with predator)/without predator. In the female mate choice experiment, the behavioural data were averaged over the three female presentations. Females were considered to have a preference for one of the males when the time spent in contact with each male differed by at least $10 \%$. Mating preference determined by the $10 \%$ difference level has been found to correlate positively with mate choice for several fish species when actual mating is allowed (reviewed by Godin \& Briggs 1996).

We used nonparametric tests when the assumption of normality was violated. We used paired tests (paired $t$ test and Wilcoxon signed-ranks test) when variates were dependent, that is, when comparing the courtship activity of the same males in the presence and absence of predators, the percentage reduction in courtship activity of competing males in the same aquaria, and the time that females spent with each of the two competing males. All probabilities are two-tailed.

\section{RESULTS}

\section{Experiment 1: Choice of Nest Site}

The presence of predators induced a preference for vegetated nest sites over open ones. Fifteeen out of 16 males chose the vegetated nest site in the presence of predators compared to five out of 16 in the absence of predators $\left(\chi_{1}^{2}=13.3, P<0.001\right)$.

\section{Experiment 2: Effect of Nest Site on Courtship and Attractiveness}

\section{Solitary and competing males}

Both solitary and competing males courted less actively in the presence of a predator, that is, they decreased the frequency of leads and the time spent courting (Figs 2, 3). The predator did not affect the frequency of zigzags of solitary males, but this could be due to the large variation between males in the frequency of zigzags and/or to zigzagging being less risky than leading under the present aquaria conditions (Candolin 1997).

The predator-induced reduction in courtship (expressed in percentages) was independent of nest site complexity in solitary males (Mann-Whitney $U$ test: $N_{1}=$ $N_{2}=20$; zigzags: $Z=0.14$, NS; leads: $Z=1.52$, NS; time courting: $Z=1.45$, NS; Fig. 2), but depended on nest site complexity in competing males: competing males in a vegetated nest site reduced their courtship activity less than competing males in an open nest site (Wilcoxon signed-ranks test: $N=20$, zigzags: $Z=3.08, P<0.01$; leads: $Z=3.60, P<0.001$; time courting: $Z=3.68, P<0.001$, Fig. 3 ). Thus, nest site had an effect on the response to a predator only when a competing male was present.

Competing males that courted live females decreased their courtship activity in the presence of a predator in the same way as competing males courting a dummy female had done: both males courted less actively, but males in an open nest site reduced their courtship activity more than males in a vegetated nest site (Wilcoxon signed-ranks test: $N=20$; difference between nest sites in the percentage reduction in zigzags: $Z=3.72$, $P<0.001$; leads: $Z=3.27, P<0.001$; time courting: $Z=3.32$, $P<0.001)$.

\section{Female mate choice}

Females reduced the time spent in a head-up posture facing the male in the open nest site when the male reduced his courtship activity (paired $t$ test: $t_{19}=5.36$, $P<0.001$ ), but did not alter the time spent facing the male in the vegetated nest site, which showed less reduction in courtship activity (paired $t$ test: $t_{19}=0.22$, NS; Fig. 4). Similarly, 32 out of 60 females preferred the male in the vegetated nest site in the absence of a predator, whereas 51 out of 60 females preferred this male in the presence of 

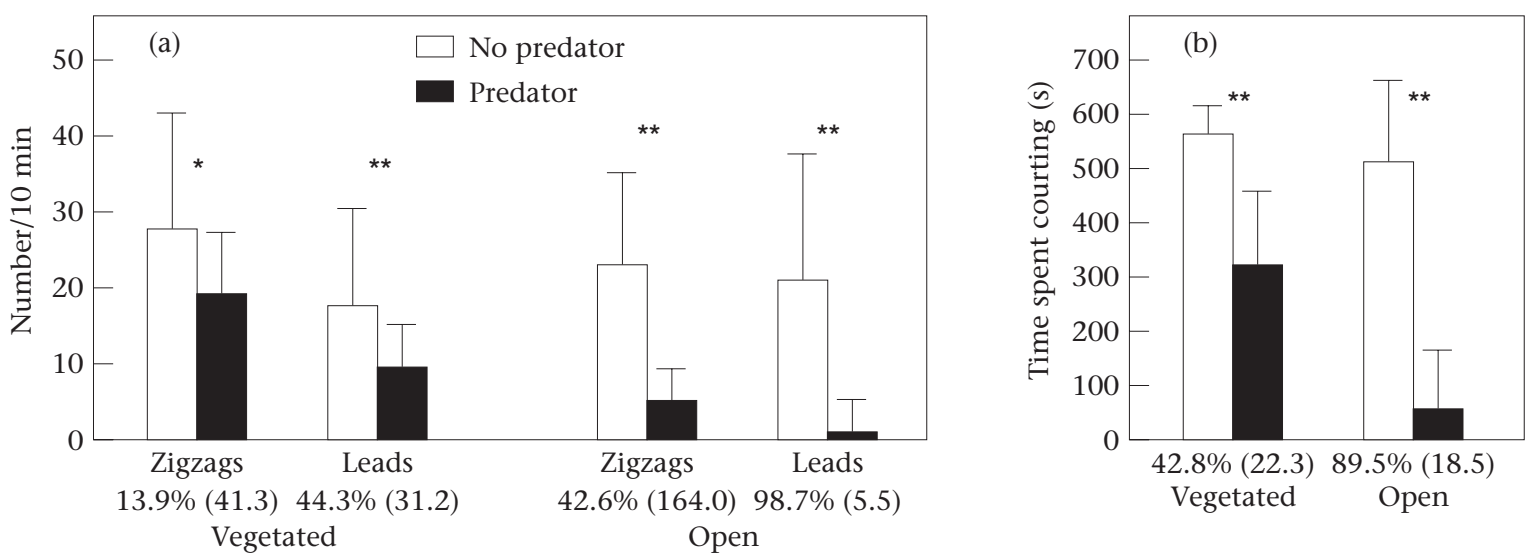

Figure 3. (a) Frequency of courtship behaviours and (b) time spent courting ( $\bar{X}+\mathrm{SD})$ of competing males, one with a vegetated nest site and the other with an open nest site, in the absence and presence of a predator, $N=20$. Wilcoxon signed-ranks test: vegetated nest site: zigzags: $Z=2.76 ; P<0.01$; leads; $Z=2.58 ; P<0.001$; time courting: $Z=3.90, P<0.001$; open nest site: zigzags: $Z=3.64$; leads: $Z=3.70$; time courting: $Z=3.90$; $P_{s}<0.001$. Percentages below bars $(\bar{X}+S D)$ show the percentage decrease in the frequencies/time due to predator treatment.

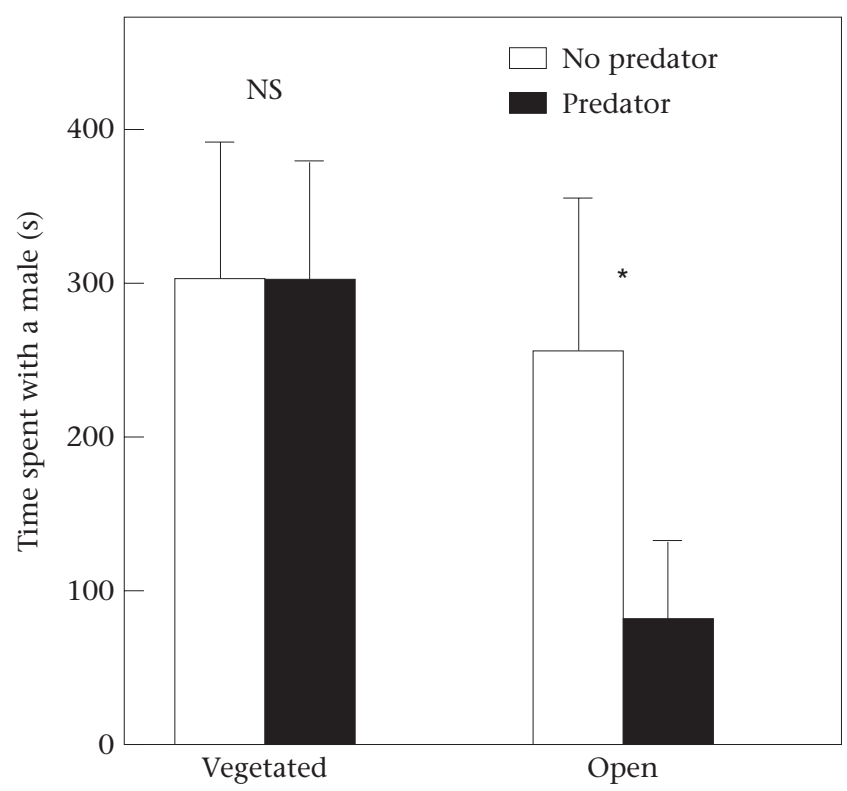

Figure 4. The time $(\bar{X}+S D)$ that females spent in a head-up posture facing each of two competing males, one with a vegetated nest site and the other with an open nest site, in the absence and presence of a predator, $N=20$. Wilcoxon signed-ranks test: ${ }^{\star} P<0.001$.

a predator $\left(\chi_{1}^{2}=14.11, P<0.001\right)$. In the absence of a predator, the structural complexity of the nest site did not affect the time females spent in a head-up position facing each male (paired $t$ test: $t_{19}=1.44$, NS; Fig. 4 ).

The colour difference between the males did not change during the brief predator presentations. Both judges found the same male to be the brighter one before and after predator presentation for all 20 male pairs (20/20, binomial test: $P<0.001)$, although they disagreed on which of the males was the brighter one for two male pairs. Thus, the alteration in female mate choice seems to have been caused by the change in male courtship activity.

\section{DISCUSSION}

We have shown that the presence of predators can induce a preference for vegetated nest sites over open ones in male three-spined sticklebacks. In the absence of predators, an open nest site may be favourable because females are more visible and more frequently encountered than in a vegetated site. When the density of predators increases, however, this benefit may be counteracted by an increased risk of predation. Complex vegetation structure is known to reduce the foraging efficiency of piscivores (e.g. Savino \& Stein 1982; Persson \& Eklöv 1995) and a preference for vegetated nest sites in the presence of predators may increase the male's probability of survival and future reproduction. Stickleback males are vulnerable to predation because of their reproductive behaviour and coloration (Moodie 1972; Whoriskey \& FitzGerald 1985). Earlier studies have found that predators force sticklebacks from the open water into the littoral zone (Jakobsen et al. 1988), and restrict the foraging of nonbreeding males to weedbeds (Ibrahim \& Huntingford 1989), but to our knowledge ours is the first study to show a predator-induced nest site preference in this species.

The aquaria experiments show that the preference for structurally complex nest sites may also benefit males by decreasing the negative effect of predators on courtship. This should affect the male's mating probability, as decreased courtship activity under predation risk reduces his attractiveness to females and thus his mating probability (Candolin 1997; Godin \& MacAulay 1997). This was also found in the present study. Females reduced their interest in the male in an open nest site when he reduced his courtship activity in the presence of a predator, but retained their interest in the male in a vegetated nest site, which showed less reduction in courtship activity. Since females showed no nest site preference in the absence of predators, and they could neither see nor smell the predator, the change in female mate preference was presumably due to predator-induced changes in the 
males. Moreover, as the difference between the males in red breeding coloration did not change during the brief predator presentation, the alteration in female mate choice seems to have been caused by the change in courtship. Consequently, the males' preference for complex nest sites in the presence of predators may both increase their probability of survival and future reproduction, and reduce the negative impact of predators on courtship and attractiveness.

In predator-rich areas the choice of nest site should thus be of crucial importance for reproductive success. This suggests that the risk of predation may be one of the important factors that influence the choice of nest site in this species. Consequently, differences in predation risk could contribute to the large difference in nest site choice both within and between populations. Earlier studies have suggested that a preference for concealed nest sites, which has been documented in some populations (e.g. Moodie 1972; Kynard 1978), may be an adaptation against nest predation and courtship interference by other males (reviewed by Rowland 1994; Whoriskey \& FitzGerald 1994). However, our study shows that the choice of complex nest sites may also benefit males by decreasing the negative effect of predators on courtship activity and attractiveness, in addition to the assumed positive effect of habitat complexity on the probability of survival.

The effect of nest site complexity on courtship activity under predation risk depended on the presence of a competing male. Solitary males decreased their courtship activity irrespective of the presence or absence of vegetation. This is probably due to the intense competition between males for females. In the field several males usually nest close to each other (the distance between nests may be as little as $20 \mathrm{~cm}$, personal observation) and even a small reduction in courtship activity compared with a neighbouring male could reduce a male's attractiveness and mating probability. Consequently, males breeding in the presence of competitors should reduce their courtship activity no more than necessary in the presence of predators, whereas solitary males may reduce courtship activity more without lowering their mating probability. Thus, our study shows that male courtship activity under predation risk depends on both the structural complexity of the nest site and the probability of losing mating opportunities to other males, that is, the presence of potential male competitors nearby.

The effect of nest site complexity on courtship activity and mating probability in the presence of predators may have profound effects on sexual selection. Predation risk has frequently been proposed to constrain the intensity of sexual selection by increasing the randomness in mate choice, that is, (1) making females less choosy (see e.g. Godin \& Briggs 1996 and references therein), (2) altering female mate choice by changing the relative attractiveness of males (Reynolds 1993; Candolin 1997; Godin \& MacAulay 1997), or (3) decreasing the opportunity for careful mate choice by either reducing the difference between males in traits that reflect mate quality or reducing the amount of information received concerning mate quality (Berglund 1993; Fuller \& Berglund 1996). How- ever, if the probability of mating under predation risk depends on nest site characteristics, intrasexual competition for favourable nest sites should increase among males and counteract the decrease in intersexual selection. Thus, the focus of sexual selection may shift from intersexual to intrasexual selection in the presence of predators. This could decrease the assumed negative effect of predation risk on the intensity of sexual selection.

\section{Acknowledgments}

We thank Jean-Guy Godin, Veijo Jormalainen and Kai Lindström for comments on the manuscript. U.C. was supported by Ella and Georg Ehrnrooth Foundation, Waldemar von Frenckell Foundation and the Swedish Cultural Foundation in Finland.

\section{References}

Anderson, O. 1984. Optimal foraging by largemouth bass in structured environments. Ecology, 65, 851-861.

Andersson, M. B. 1994. Sexual Selection. Princeton, New Jersey: Princeton University Press.

Berglund, A. 1993. Risky sex: male pipefishes mate at random in the presence of a predator. Animal Behaviour, 46, 169-175.

Candolin, U. 1997. Predation risk affects courtship and attractiveness of competing threespine stickleback males. Behavioral Ecology and Sociobiology, 41, 81-87.

Endler, J. A. 1983. Natural and sexual selection on colour patterns in poeciliid fishes. Environmental Biology of Fishes, 9, 173-190.

Farr, J. A. 1975. The role of predation in the evolution of social behaviour of natural populations of the guppy, Poecilia reticulata (Pisces: Poeciliidae). Evolution, 29, 151-158.

Farr, J. A. 1980. Social behaviour as determinants of reproductive success in the guppy, Poecilia reticulata Peters (Pisces: Poeciliidae). Behaviour, 74, 38-91.

Fuller, R. \& Berglund, A. 1996. Behavioural responses of a sexrole reversed pipefish to a gradient of perceived predation risk. Behavioral Ecology, 7, 69-75.

Godin, J.-G. J. 1995. Predation risk and alternative mating tactics in male Trinidadian guppies (Poecilia reticulata). Oecologia, 103, 224-229.

Godin, J.-G. J. \& Briggs, S. E. 1996. Female mate choice under predation risk in the guppy. Animal Behaviour, 51, 117-130.

Godin, J.-G. J. \& MacAulay, A. 1997. Predator-mediated changes in male courtship affect female mate choice in sticklebacks. Advances in Ethology, 32, 205.

Gwynne, D. T. 1989. Does copulation increase the risk of predation? Trends in Ecology and Evolution, 4, 54-56.

Hastings, P. A. 1991. Flexible responses to predators in a marine fish. Ethology, Ecology and Evolution, 3, 177-184.

Houde, A. E. 1988. The effects of female mate choice and malemale competition on the mating success of male guppies. Animal Behaviour, 36, 888-896.

Ibrahim, A. A. \& Huntingford, F. A. 1989. Laboratory and field studies of the effect of predation risk on foraging in three-spined sticklebacks (Gasterosteus aculeatus). Behaviour, 109, 46-57.

Jakobsen, P. J., Johnsen, G. H. \& Larsson, P. 1988. Effects of predation risk and parasitism on the feeding ecology, habitat use, and abundance of lacustrine threespine stickleback (Gasterosteus aculeatus). Canadian Journal of Fisheries and Aquatic Science, 45, 426-431. 
Kodric-Brown, A. 1993. Female choice of multiple male criteria in guppies: interacting effects of dominance, coloration and courtship. Behavioral Ecology and Sociobiology, 32, 415-420.

Kynard, B. E. 1978. Breeding behavior of a lacustrine population of threespine sticklebacks (Gasterosteus aculeatus L.). Behaviour, 67, 178-207.

Lima, S. L. \& Dill, L. M. 1990. Behavioral decisions made under the risk of predation: a review and prospectus. Canadian Journal of Zoology, 68, 619-640.

Magnhagen, C. 1991. Predation risk as a cost of reproduction. Trends in Ecology and Evolution, 6, 183-186.

Moodie, G. E. E. 1972. Predation, natural selection and adaptation in an unusual threespine stickleback. Heredity, 28, 155-167.

ter Pelkwijk, J. J. \& Tinbergen, N. 1937. Eine reizbiologische Analyse einiger Verhaltensweisen von Gasterosteus aculeatus L. Zeitschrift für Tierpsychologie, 1, 193-200.

Persson, L. \& Eklöv, P. 1995. Prey refuges affecting interactions between piscivorous perch and juvenile perch and roach. Ecology, 76, 70-81.

Reynolds, J. D. 1993. Should attractive individuals court more? Theory and a test. American Naturalist, 141, 914-927.

Rowland, W. J. 1994. Proximate determinants of stickleback behaviour: an evolutionary perspective. In: The Evolutionary Biology of the Threespine Stickleback. (Ed. by M. A. Bell \& S. A. Foster), pp. 297-344. Oxford: Oxford University Press.
Savino, J. F. \& Stein, R. A. 1982. Predator-prey interactions between largemouth bass and bluegills by simulated, submerged vegetation. Transactions of the American Fisheries Society, 111, 255-266.

Savino, J. F. \& Stein, R. A. 1989. Behavioural interactions between fish predators and their prey: effect of plant density. Animal Behaviour, 37, 311-321.

Sih, A. 1988. The effects of predators on habitat use, activity and mating behaviour of a semi-aquatic bug. Animal Behaviour, 36, 1846-1848.

Sih, A. 1994. Predation risk and the evolutionary ecology of reproductive behaviour. Journal of Fish Biology, 45 (Suppl. A), 111-130.

Sih, A., Krupa, J. \& Travers, S. 1990. An experimental study on the effects of predation risk and feeding regime on the mating behavior of the water strider. American Naturalist, 135, 284290.

Whoriskey, F. G. \& FitzGerald, G. J. 1985. The effects of bird predation on an estuarine stickleback (Pisces: Gasterosteidae) community. Canadian Journal of Zoology, 63, 301-307.

Whoriskey, F. G. \& FitzGerald, G. J. 1994. Ecology of the threespine stickleback on the breeding grounds. In: The Evolutionary Biology of the Threespine Stickleback (Ed. by M. A. Bell \& S. A. Foster), pp. 188-206. Oxford: Oxford University Press. 